\title{
VARIABEL DATA LALU LINTAS ANTARA PERANGKAT DETEKTOR KENDARAAN DARI ATCS DENGAN DATA DARI METODE MANUAL PENCACAHAN LALU LINTAS TERKLASIFIKASI DAN SPOT SPEED (EMPIRIS)
}

\author{
FX. Bowo Priyambodo, S.SiT, M.Sc \\ Dosen STTD
J1. Raya Setu No. 89, Cibuntu, Cibitung, Bekasi 17520 \\ Telp./Fax : (021) 8254640
}

\author{
Drs. Eko Sudriyanto, MM, MSi \\ Dosen STTD \\ Jl. Raya Setu No. 89, Cibuntu, \\ Cibitung, Bekasi 17520 \\ Telp./Fax : (021) 8254640
}

\author{
Budiharso Hidayat, ATD, MT \\ Dosen STTD \\ J1. Raya Setu No. 89, Cibuntu, \\ Cibitung, Bekasi 17520 \\ Telp./Fax : (021) 8254640
}

\author{
Rianto Rili, ST, M.Sc \\ Dosen STTD \\ J1. Raya Setu No. 89, Cibuntu, \\ Cibitung, Bekasi 17520 \\ Telp./Fax : (021) 8254640
}

\author{
Boby Hermawan, MT \\ Dosen STTD \\ J1. Raya Setu No. 89, Cibuntu, \\ Cibitung, Bekasi 17520 \\ Telp./Fax : (021) 8254640
}

\begin{abstract}
ABSTRAKSI
Data pencacahan volume lalu lintas merupakan informasi dasar yang diperlukan untuk fase perencanaan, desain, manajemen sampai pengoperasian jalan. Survai volume lalu lintas bertujuan untuk mencatat setiap kendaraan yang lewat (melewati suatu titik atau garis tertentu) sehingga didapatkan informasi mengenai pola arus lalu lintas, volume lalu lintas tiap pergerakan, komposisi kendaraan dalam lalu lintas, faktor untuk memprediksi volume lalu lintas yang akan dating, tingkat okupansi kendaraan dalam lalu lintas dan volume pejalan kaki

Adapun perkembangan teknologi dalam bidang transportasi saat ini semakin pesat, dengan perangkat ini, surveyor tidak perlu melakukan kegiatan pengambilan data di lapangan.

Dalam peneltian Ofyar Z. Tamin \& Rusmadi Suyuti, 2007, tentang meningkatkan akurasi Matriks Asal Tujuan menggunakan data lalu lintas. Ofyar mengkaji dari sisi setelah data volume didapatkan dari ATCS kemudian dilakukan kalibrasi dalam metode estimasi untuk mendapatkan sebaran pergerakan, akan tetapi jika data dari ATCS tersebut belum akurat atau mendekati kondisi lapangan, baik komposisi maupun jumlah kendaraan maka prediksi tersebut menjadi bias dan model yang dihasilkan belum menyerupai kondisi di lapangan.

Kata Kunci: ATCS, Kalibrasi, Lalu lintas
\end{abstract}

\section{ABSTRACT}

Enumeration of data traffic volume is basic information that necessary for the planning, design, management to the operation of the road. Traffic volume Survey aims to record every vehicle that passes (pass a point or a certain line) to obtain information about the pattern of traffic flow, traffic volume of each movement, the composition of the vehicle in traffic, factors to predict the volume of traffic that will come, the occupancy rate of vehicles in traffic and pedestrian volume

The technological developments in the transport sector is currently growing rapidly, with this device, the surveyor does not need to conduct data collection in the field.

In the course of a study Ofyar Z. Tamin \& Rusmadi Suyuti, 2007, on improving the accuracy of an Origin purpose of using traffic data. Ofyar reviewing the terms after the volume data obtained from ATCS then be calibrated in the estimation method to obtain the distribution of the movement, but if the data from ATCS are not accurate or close to field conditions, both the composition and the number of 
vehicles that such predictions to be biased and the resulting model yet resembles the conditions on the ground.

\section{Keywords: ATCS, Calibration, Traffic}

\section{PENDAHULUAN}

\section{A. LATAR BELAKANG}

Penggunaan data volume saat ini cukup berkembang tidak hanya untuk melihat kinerja suatu ruas maupun jaringan jalan, akan tetapi berkembang hingga dapat dijadikan komponen dalam memprediksi pergerakan perjalanan (Ofyar Z. Tamin, 1988).

Data pencacahan volume lalu lintas merupakan informasi dasar yang diperlukan untuk fase perencanaan, desain, manajemen sampai pengoperasian jalan. Survai volume lalu lintas bertujuan untuk mencatat setiap kendaraan yang lewat (melewati suatu titik atau garis tertentu) sehingga didapatkan informasi mengenai pola arus lalu lintas, volume lalu lintas tiap pergerakan, komposisi kendaraan dalam lalu lintas, faktor untuk memprediksi volume lalu lintas yang akan dating, tingkat okupansi kendaraan dalam lalu lintas dan volume pejalan kaki Adapun perkembangan teknologi dalam bidang transportasi saat ini semakin pesat, dengan perangkat ini, surveyor tidak perlu melakukan kegiatan pengambilan data di lapangan.

Dalam peneltian Ofyar Z. Tamin \& Rusmadi Suyuti, 2007, tentang meningkatkan akurasi Matriks Asal Tujuan menggunakan data lalu lintas. Ofyar mengkaji dari sisi setelah data volume didapatkan dari ATCS kemudian dilakukan kalibrasi dalam metode estimasi untuk mendapatkan sebaran pergerakan, akan tetapi jika data dari ATCS tersebut belum akurat atau mendekati kondisi lapangan, baik komposisi maupun jumlah kendaraan maka prediksi tersebut menjadi bias dan model yang dihasilkan belum menyerupai kondisi di lapangan.

\section{B. RUMUSAN MASALAH}

1 Mampukah perangkat detektor menghasilkan data volume pencacahan lalu lintas terklasifikasi ?

2 Seberapa besar perbedaan volume dan kecepatan kedua metoda pencacahan lalu lintas terklasifikasi ?

3 Berapa nilai koreksi dari data volume pencacahan lalu lintas terklasifikasi yang dihasilkan oleh perangkat detektor agar dapat digunakan sebagai alat alternatif mendapatkan data volume pencacahan lalu lintas terklasifikasi ? 


\section{TUJUAN PENELITIAN}

Penelitian ini bertujuan :

1. Memberikan penilaian seberapa besar ketepatan data volume dan kecepatan yang dihasilkan oleh perangkat detektor.

2. Memberikan nilai faktor koreksi agar data volume dan kecepatan yang dihasilkan oleh perangkat detektor dapat digunakan.

\section{RUANG LINGKUP PENELITIAN}

Ruang lingkup dari penelitian ini terdiri dari :

1. Ruang Lingkup Wilayah

Ruang lingkup wilayah untuk kegiatan penelitian ini adalah Jl. Raya Setu di depan

Sekolah Tinggi Transportasi Darat dan Persimpangan Stagger Jl. Kalimalang - Jl.

Kampung Utan. Penelitian dilakukan selama 4 (empat) bulan.

2. Ruang Lingkup Kegiatan

- lokasi studi ditentukan pada Jl. Raya Setu di depan Sekolah Tinggi Transportasi Darat dan Persimpangan Stagger J1. Kalimalang - Jl. Kampung Utan, mengingat kedua lokasi tersebut memiliki perangkat detektor kendaraan yang dipasang pada lokasi tersebut.

- Kinerja lalu lintas yang dikaji pada penelitian ini adalah volume lalu lintas kendaraan dan kecepatan kendaraan pada ruas jalan.

- Validitas data yang diperoleh dari perangkat detektor kendaraan didapat dari proses kalibrasi data dalam pemberian nilai koreksi dari perangkat detektor dengan data survai pencacahan lalu lintas terklasifikasi.dan spot speed.

- Faktor SMP menggunakan nilai yang dianut pada perangkat detektor.

\section{LANDASAN TEORI}

1. Karakteristik Lalu Lintas

\section{Survai Volume Lalu Lintas Terklasifikasi}

Pencacahan volume lalu lintas secara manual dapat dengan mudah dilakukan dengan menghitung jumlah kendaraan per satuan waktu berdasarkan kelas-kelasnya. Data volume lalu lintas terklasifikasi digunakan untuk :

a. desain geometrik jalan (kecepatan desain, kelandaian, radius) 
b. desain struktur konstruksi perkerasan jalan dan jembatan

c. manajemen lingkungan (kebisingan, asap, getaran), manajemen angkutan barang dan manajemen angkutan umum

d. perhitungan ekonomi termasuk biaya operasi kendaraan, nilai waktu orang (personel time), biaya kelambatan dan lain-lain

e. penyesuaian hasil pembacaan dengan alat pencacah mekanis

\section{Metoda survai manual}

Pembagian jenis kendaraan dalam lalu lintas disesuaikan dengan tujuan survai, misalnya : dibedakan antara yang bermotor dan tidak bermotor, dibedakan antara yang bermesin disel dengan yang bukan disel, dibedakan antara tiap jenis kendaraan yang ada, dibedakan atas satuan mobil penumpang tiap kendaraan.

Berikut ini diberikan contoh pembagian kendaraan bermotor :

(1) kendaraan bermotor beroda dua,

(2) mobil penumpang : sedan, taksi, minicab (Suzuki, zebra, Mitsubishi), vans (combi kijang, panther), jeep (jimmy, taft, hardtop, dll),

(3) bis,

(4) kendaraan angkutan barang (truk kecil) sampai dengan 2 ton,

(5) kendaraan angkutan barang (truk sedang) sampai dengan 2-8 ton,

(6) kendaraan angkutan barang (truk besar) lebih dari 8 ton.

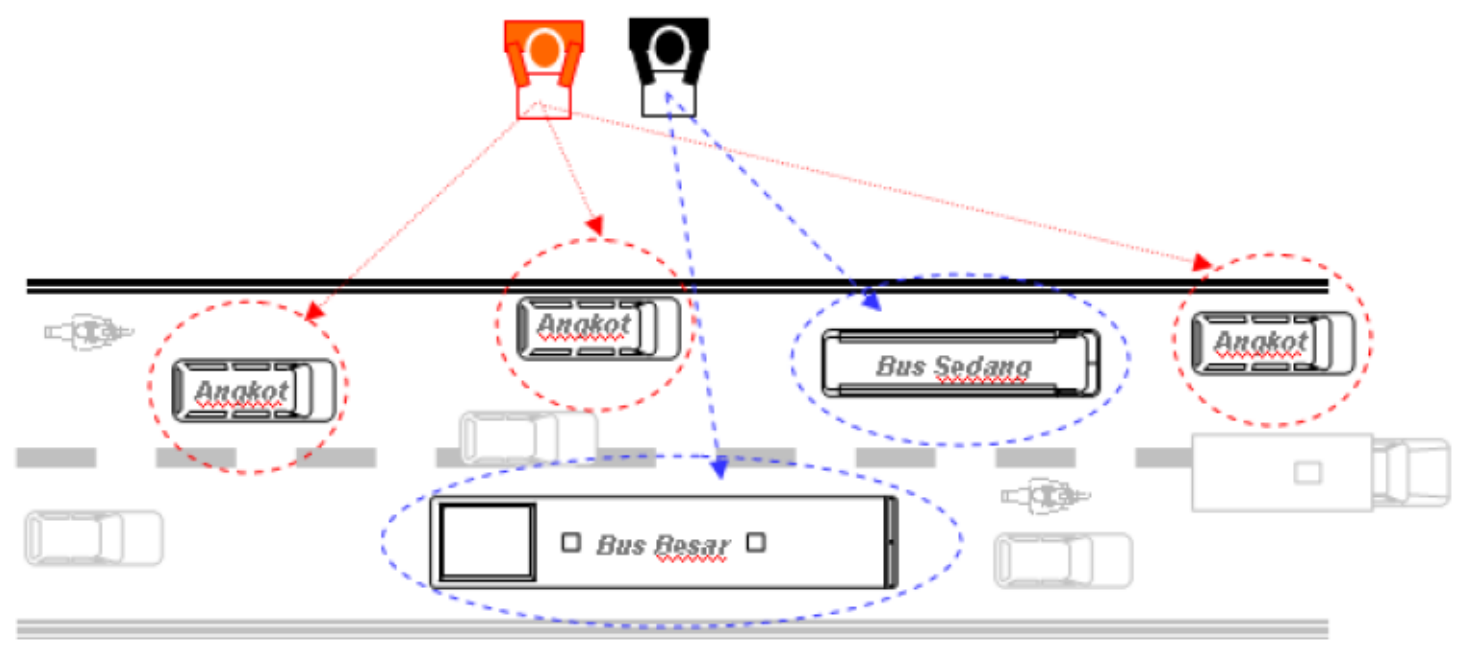

Gambar 2.1 Ilustrasi penempatan petugas survai pencacahan lalu lintas secara manual 


\section{Metoda Pencacahan Otomatis}

Untuk mendapatkan variasi harian, bulanan dan tahunan, maka survai harus dilakukan untuk periode waktu yang cukup panjang, tidak cukup hanya dengan survai sehari. Dengan demikian, alat yang dapat mencacah secara otomatis digunakan. Alat pencacah otomatis umumnya terdiri dari detector yang mendeteksi kendaraan yang melintasinya, dan alat pencatat mekanik atau elektronik yang mencatat/mendeteksi setiap kendaraan yang melalui detector, belakangan ini dikembangkan kamera video yang diperlengkapi dengan alat pendeteksi kendaraan secara visual. Berbagai sistem pencacah otomatis yang biasanya langsung dihubungkan dengan komputer untuk kemudahan dan kecepatan permrosesan data selanjutnya, antara lain :

(1) Selang udara (pneumatic tube)

(2) Pelat elektrik

(3) Induksi putar

(4) Radar

(5) Detektor ultrasonik

(6) Video Image Processor

(7) Alat pencatat dan peraga

2. Perbandingan data sekunder dengan data empiris $\rightarrow$ Regresi sederhana, Dari hasil survai TC di tetapkan sebagai data variabel terikat dan data ATCS sebagai variabel bebas. Didalam melakukan perbandingan data maka perlu ditentukan dahulu variabel - variabel yang dianggap mewakili dan saling berkorelasi. Untuk itu perlu diketahui koefisien dari masing-masing variabel untuk :

a) Jumlah data TC (Y)

b) Data ATCS (X1)

Setelah dilakukan perhitungan terhadap koefisien korelasi tersebut, kemudian dicari hubungan atau korelasi variable bebas dengan variable tidak bebas maupun hubungan antara variable bebas dengan variable bebas yang lain, yaitu :

$\begin{array}{ll}\text { Y dengan X1 : } & \text { X1 dengan X2 } \\ \text { Y dengan X2 : } & \text { X1 dengan X3 } \\ \text { Y dengan X3 : } & \text { X2 dengan X3 } \\ \text { Untuk : } & \\ \text { Y = Jumlah Data TC } \\ \text { X1 = Jumlah data ATCS }\end{array}$


Secara geometrik, titik-titik hasil eksperimen, model dan error digambarkan pada grafik berikut ini :

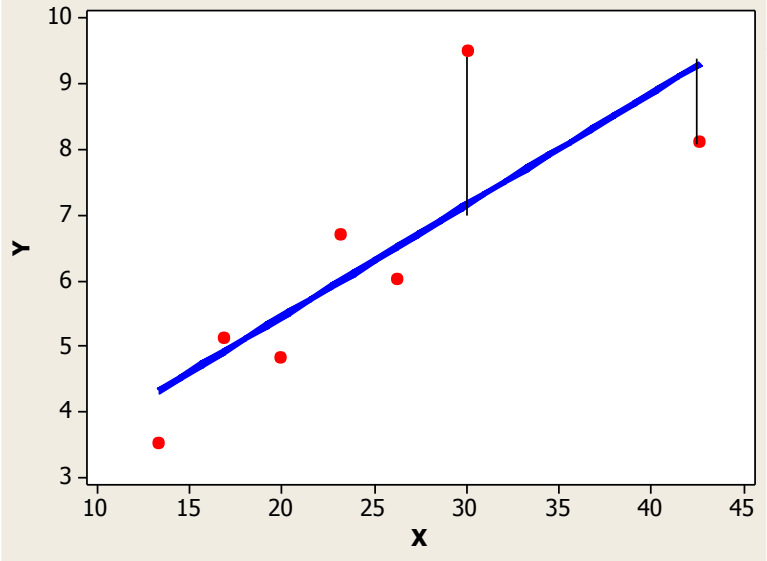

Titik-titik merah adalah nilai hasil eksperimen, di-notasikan $Y_{\mathrm{i}}$, yang diduga membentuk garis lurus berwarna biru. Garis inilah model yang akan di-taksir, dengan cara menaksir koefisiennya, yaitu $b_{0}$ dan $b_{1}$, sehingga terbentuk persamaan $\hat{Y}_{i}=b_{0}+b_{1} X_{\mathrm{i}}$. 


\section{A. Metode Analisis Data}

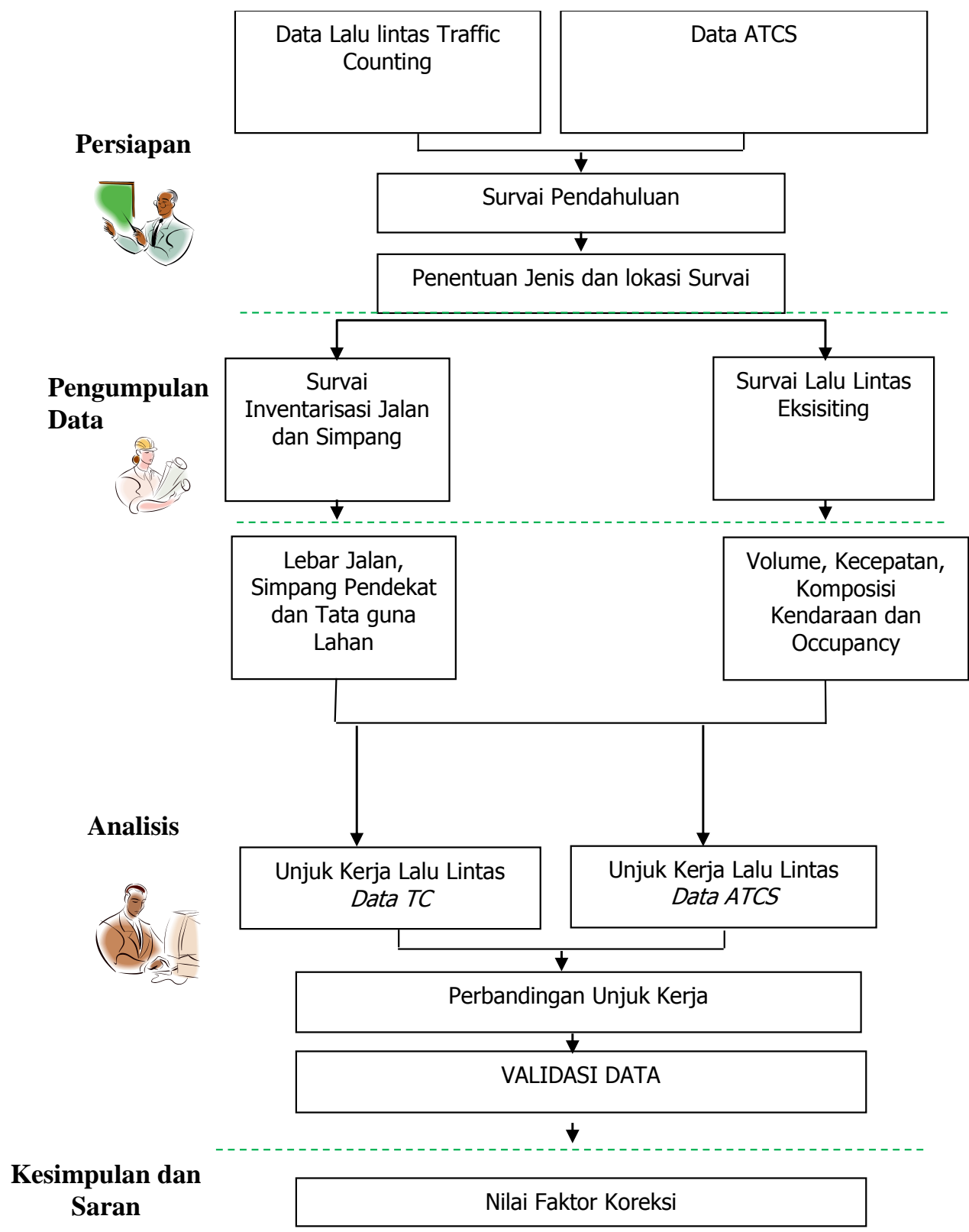

Gambar 3.1 Bagan alir penelitian 


\section{HASIL PENGUMPULAN DATA}

\section{A. HASIL SURVAI TRAFFIC COUNTING}

Survai inventarisasi ruas jalan dilakukan untuk mengetahui karakteristik lalu lintasdi jalan raya setu. Dari survai ini dapat diperoleh data mengenai geometrik jalan, tata guna lahan disekitarnya, luas lahan dan lain - lain.

Survai pencacahan lalu lintas ruas jalan terklasifikasi dilakukan pada ruas jalan raya satu, Hasil survai pencacahan lalu lintas terklasifikasi pada masing - masing ruas jalan selengkapnya dapat dilihat pada tabel berikut ini.

1. Ruas Jalan Setu Arah Cibuntu ke Kalimalang

Berdasarkan grafik lalu lintas dari Ruas Jalan Setu Arah Cibuntu ke Kalimalang diatas menjelaskan bahwa :

> Waktu sibuk lalu lintas dari Setu menuju Kali malang terjadi pada pukul 16.30 17.30 WIB dengan volume lalu lintas sebesar 2117,3 smp / jam.

$>$ Presentase jenis kendaraan terbanyak adalah sepeda motor dengan presentase sebesar 95,29\% dari total kendaraan untuk arah lalu lintas.

2. Ruas Jalan Setu Arah Kalimalang ke Cibuntu

Berdasarkan grafik lalu lintas dari Ruas Jalan Setu Arah Cibuntu ke Kalimalang diatas menjelaskan bahwa :

$>$ Waktu sibuk lalu lintas dari Setu menuju Kali malang terjadi pada pukul 06.30 07.30 WIB dengan volume lalu lintas sebesar 1.574,9 smp / jam.

$>$ Presentase jenis kendaraan terbanyak adalah sepeda motor dengan presentase sebesar 95,59\% dari total kendaraan untuk arah lalu lintas.

\section{B. HASIL DATA ATCS}

Data ATCS didapatkan dari data LAB ATCS di Sekolah Tinggi Transportasi Darat yang dilakukan untuk mengetahui karakteristik lalu lintasdi jalan raya setu sesuai dengan menggunakan sensor kamera otomatis. Dari data ini dapat diperoleh data volume lalu lintas sesuai rekap data statistic ATCS. Survai pencacahan lalu lintas ruas jalan terklasifikasi dilakukan pada ruas jalan raya satu, Hasil survai pencacahan lalu lintas terklasifikasi pada masing - masing ruas jalan selengkapnya dapat dilihat pada tabel berikut ini.

1. Ruas Jalan Setu Arah Cibuntu ke Kalimalang 
Berdasarkan grafik lalu lintas dari Ruas Jalan Setu Arah Cibuntu ke Kalimalang diatas menjelaskan bahwa :

Waktu sibuk lalu lintas dari Setu menuju Kali malang terjadi pada pukul 06.30 07.30 WIB.

$>$ Presentase jenis kendaraan terbanyak adalah sepeda motor dengan presentase sebesar $55 \%$ dari total kendaraan untuk arah lalu lintas.

2. Ruas Jalan Setu Arah Kalimalang ke Cibuntu

Berdasarkan grafik lalu lintas dari Ruas Jalan Setu Arah Cibuntu ke Kalimalang diatas menjelaskan bahwa :

$>$ Waktu sibuk lalu lintas dari Setu menuju Kali malang terjadi pada pukul 06.30 07.30 WIB.

$>$ Presentase jenis kendaraan terbanyak adalah kendaraan kecil dengan presentase sebesar $57 \%$ dari total kendaraan untuk arah lalu lintas .

Hasil dari data ATCS selanjutnya dibandingkan dengan data volume lalu lintas hasil survei. Untuk menilai baik atau tidaknya model jaringan yang telah dibuat perlu dilakukan validasi dengan uji statistik. Uji statistic yang digunakan untuk menguji apakah hasil pemodelan yang dihasilkan dapat diterima atau tidak adalah Chi-Kuadrat terhadap data survey berikut adalah langkah-langkah validasi data ATCS dengan hasil survei lalu lintas :

Menentukan hipotesis nol dan hipotesisi alternatifnya.

Hasil dari data ATCS selanjutnya dibandingkan dengan data volume lalu lintas hasil survei. Untuk menilai baik atau tidaknya model yang telah dibuat perlu dilakukan validasi dengan uji statistik. Uji statistik yang digunakan untuk menguji apakah hasil pemodelan yang dihasilkan dapat diterima atau tidak adalah Uji Chi-square terhadap data hasil survey. Sebelum melakukan validasi. terlebih dahulu perlu ditentukan hipotesis nol dan hipotesis altenatifnya yaitu :

$\mathrm{H}_{\mathrm{o}} \quad$ : hasil survei $(\mathrm{Oi})=$ hasil model $(\mathrm{Ei})$

$\mathrm{H}_{1} \quad$ : hasil survei $(\mathrm{Oi}) \neq$ hasil model (Ei)

Tingkat signifikan yang dipakai adalah 95 atau $\alpha=0.05$

Derajat kebebasan $=10-1=9$

Dengan $\alpha=0.05$ dan $\mathrm{df}=9$

maka Chi-square $\left(\chi^{2}\right)$ tabel $=16.919$

$\mathrm{H}_{\mathrm{o}}$ diterima jika $: \chi^{2}$ hasil hitungan $<\chi^{2}$ hasil tabel

$\mathrm{H}_{1}$ ditolak jika $\chi^{2}$ hasil hitungan $>\chi^{2}$ hasil tab 
Berikut adalah perhitungan Chi-kuadrat untuk ruas Jl. kalimalang. sebagai berikut :

$$
\begin{aligned}
& \text { v/c hasil survei } \quad: 0.73 \\
& \text { v/c hasil model }: 0.66 \\
& \begin{aligned}
&\left(\chi^{2}\right) \quad=(0.73-0.66)^{2} / 0.66 \\
&=(0.07)^{2} / 0.66 \\
&= 0.002
\end{aligned}
\end{aligned}
$$

\begin{tabular}{|c|c|c|c|c|c|c|c|c|}
\hline \multirow{2}{*}{ NO } & \multirow{2}{*}{$\begin{array}{l}\text { NODE } \\
\text { AWAL }\end{array}$} & \multirow{2}{*}{$\begin{array}{l}\text { NODE } \\
\text { AKHIR }\end{array}$} & \multirow{2}{*}{ NAMA JALAN } & \multirow{2}{*}{$\begin{array}{l}\text { PANJANG } \\
\text { JALAN }\end{array}$} & \multirow{2}{*}{ FUNGSI JALAN } & \multicolumn{2}{|c|}{ V/C RATIO } & \multirow{2}{*}{$\begin{array}{c}\text { Chi - } \\
\text { Kuadrat } \\
\mathbf{X}^{2}\end{array}$} \\
\hline & & & & & & SURVEI & MODEL & \\
\hline 1 & 301 & 303 & $\begin{array}{c}\text { Bandung (Kopo) - } \\
\text { Soreang VII }\end{array}$ & 2.70 & Arteri Primer & 0.83 & 0.69 & 0.030 \\
\hline 2 & 903 & 902 & $\begin{array}{c}\text { Bandung (Kopo) - } \\
\text { Soreang IV }\end{array}$ & 1.50 & Arteri Primer & 0.72 & 0.58 & 0.035 \\
\hline 3 & 903 & 1401 & Sayati - Palasari & 1.70 & Kolektor Primer & 0.80 & 0.64 & 0.038 \\
\hline 4 & 902 & 901 & $\begin{array}{c}\text { Bandung (Kopo) - } \\
\text { Soreang V }\end{array}$ & 1.50 & Arteri Primer & 0.73 & 0.66 & 0.008 \\
\hline 5 & 1001 & 1504 & $\begin{array}{c}\text { Jl. Raya Banjaran } \\
\text { VI }\end{array}$ & 0.60 & Kolektor Primer & 0.61 & 0.64 & 0.001 \\
\hline 6 & 1106 & 1109 & $\begin{array}{c}\text { Jl. Raya Banjaran } \\
\text { III }\end{array}$ & 0.60 & Kolektor Primer & 0.77 & 0.61 & 0.043 \\
\hline 7 & 1101 & 1105 & Jl. Raya Banjaran I & 0.65 & Kolektor Primer & 0.73 & 0.61 & 0.023 \\
\hline 8 & 1401 & 903 & Sayati - Palasari & 1.50 & Kolektor Primer & 0.78 & 0.73 & 0.004 \\
\hline 9 & 1802 & 1404 & $\begin{array}{l}\text { Dayeuhkolot - } \\
\text { Bojongsoang }\end{array}$ & 1.00 & Kolektor Primer & 0.65 & 0.60 & 0.004 \\
\hline 10 & 1901 & 2501 & J1. Raya Laswi I & 5.03 & Arteri Primer & 0.69 & 0.74 & 0.003 \\
\hline \multicolumn{8}{|c|}{ Jumlah } & 0.189 \\
\hline
\end{tabular}

Berikut adalah tabel yang menunjukkan hasil nilai chi-kuadrat untuk ruas jalan kalimalang.

Tabel IV. 21 : Validasi Hasil ATCS dengan Hasil Survei

Sumber : Hasil Analisis 


\section{Validasi Model Tarikan Perjalanan yang Telah Terbentuk}

Agar model yang telah terbentuk dapat digunakan, untuk memprediksi besaran data survey dengan variabel data ATCS, maka perlu dilakukan validasi model dengan hasil observasi atau survei wawancara yang telah dilakukan.

Dalam melakukan validasi model digunakan Uji- $t$ Sampel-Ganda Untuk table pembandingan tarikan perjalanan antara hasil model dengan hasil observasi dapat dilihat pada Lampiran 2. Adapun pernyataan hipotesis untuk mengetahui adanya perbedaan diantara kedua jumlah tarikan perjalanan, sebagai berikut:

$\mathrm{H}_{0}=$ Hasil model tidak ada perbedaan dengan Hasil observasi

$\mathrm{H}_{1}=$ Hasil model ada perbedaan dengan Hasil observasi.

Untuk aturan keputusan:

Tolak $\mathrm{H}_{0}$ dan terima $\mathrm{H}_{1}$ jika $t$ hitung $> \pm$ 1.990. Jika tidak demikian terima $\mathrm{H}_{0}$.

Dengan memilih tingkat kepentingan (Level of Significance) $95 \%$, maka dengan derajat kebebasan $(d f)=n-1=466-1=465$, sehingga $t$ tabelnya adalah 1,648. adapun hasil Uji- $t$ sebagai berikut:

Tabel V.36 Hasil Uji-t untuk Validasi Model Perbandingan ATCS

t-Test: Paired Two Sample for Means

\begin{tabular}{lrr}
\hline & $Y$ & Ypredicted \\
\hline Mean & 247.2386 & 247.0536 \\
Variance & 240379.3 & 154069.2 \\
Observations & 466 & 466 \\
Pearson Correlation & 0.798323 & \\
Hypothesized Mean Difference & 0 & \\
df & 465 & \\
t Stat & 0.013523 \\
P(T<=t) one-tail & 0.494608 & \\
t Critical one-tail & 1.648137 & \\
P(T<=t) two-tail & 0.989216 & \\
t Critical two-tail & 1.965079 & \\
\hline
\end{tabular}


Dari Tabel V.36 diketahui bahwa t hitung untuk model tarikan perjalanan ke-6 kecamatan adalah sebesar 0,0135, hal ini berarti bahwa t hitung/t Stat $<$ dari $\mathrm{t}$ tabel, berarti $\mathrm{H}_{0}$ diterima atau hasil perjalanan dari model tidak ada perbedaan dengan hasil survey wawancara tarikan perjalanan, dengan nilai Korelasi Pearson sebesar 0,798.

\section{DAFTAR PUSTAKA}

, (2000), Keputusan Menteri Pendidikan Nasional Nomor 232/U/2000 tentang Pedoman Penyusunan Kurikulum Pendidikan Tinggi dan Penilaian Hasil Belajar Mahasiswa.

, (2002), Keputusan Menteri Pendidikan Nasional Nomor 045/U/2002 tentang Kurikulum Inti Pendidikan Tinggi.

, (2003), Undang - Undang Nomor 20 Tahun 2003 tenteng Sistem Pendidikan Nasional.

E. Mulyasa, (2002), Kurikulum Berbasis Kompetensi, Penerbit Remaja Rosdakarya, Bandung.

Sugiyono, (2007), Statistik Untuk Penelitian, Edisi kedua belas, Alfabeta, Bandung.

Ibrahim dan N. Sudjana, Penelitian dan Penilaian Pendidikan, Penerbit Sinar Baru, Bandung. 